\title{
Pedro A. San Martín y la recuperación del patrimonio monumental murciano: los palacios de Guevara, Riquelme y el Contraste
}

\author{
SILVIA GARCÍA ALCÁZAR \\ Universidad de Castilla-La Mancha
}

Recibido: 09-05-2019

Aprobado: 19-07-2019

\section{RESUMEN}

Pedro San Martín Moro fue un arquitecto y arqueólogo estrechamente vinculado con la Región de Murcia y la salvaguarda de su patrimonio monumental durante el periodo del Desarrollismo franquista. En 1963 fue nombrado Arquitecto ayudante de la Séptima Zona siendo, de facto, quien asumió los trabajos de restauración de edificios y yacimientos arqueológicos de la región. Precisamente el patrimonio arquitectónico de la región venía experimentando importantes cambios, daños y pérdidas. Así pues, intervino edificios aún en uso que, afortunadamente, no corrían un peligro acuciante de desaparición como el caso del Palacio de Guevara en Lorca. Pero también asumió retos más arriesgados como el caso de los Palacios de Riquelme y del Contraste de la Seda, ambos en Murcia, de los que, tras diferentes avatares, solo se conservaron sus portadas que fueron recuperadas por San Martín y reutilizadas en otros emplazamientos.

PALABRAS CLAVE: Pedro San Martín Moro / Murcia / Palacio de Guevara / Palacio de Riquelme / Contraste de la Seda.

\section{ABSTRACT}

Pedro San Martín Moro was an architect and archaeologist who worked in the conservation of the monumental heritage of the Region of Murcia during Desarrollismo. In 1967 he was designated Assistant Architect in the "Septima Zona" restoring important buildings and archaeological sites. He also worked with the damaged architectural heritage like the palaces of Guevara at Lorca, Riquelme and Contraste de la Seda, at Murcia both of them. The first one just had an aesthetic restoration to return it to its original state. Of the other two palaces just remained their façades that were recovered by San Martín and reused in new places.

KEY WORDS: Pedro San Martín Moro / Murcia / Palace of Guevara / Palace of Riquelme / Contraste de la Seda. 


\section{Introducción}

El presente texto tiene como objetivo ahondar en el conocimiento de una figura clave para la historia de la restauración de monumentos de nuestro país, el arquitecto Pedro Antonio San Martín Moro (1921-2013), a través de una pequeña representación del amplio trabajo que desempeñó durante décadas en la Región de Murcia. Antes de continuar, es necesario reseñar que este estudio ha sido realizado en el marco del proyecto de investigación Los arquitectos restauradores de la España del franquismo. De la continuidad de la ley de 1933 a la recepción de la teoría europea (ref. HAR2015-68109-P), financiado por el Ministerio de Economía y Competitividad y los fondos FEDER. Ello ha establecido el marco temporal en el que nos moveremos, abordando la práctica restauradora de San Martín desarrollada durante las décadas de los 60 y 70 del siglo XX.

Nacido en Valladolid en mayo de 1921, Pedro San Martín ejerció su labor como arquitecto vinculado a la región murciana durante toda su vida. Su formación la desarrolló desde finales de los años 40 al ingresar en la Escuela Superior de Arquitectura de Madrid donde fue alumno de Leopoldo Torres Balbás, influencia presente y visible en muchos de sus trabajos. Se tituló en 1953 y al año siguiente obtuvo plaza como arquitecto de la Hacienda Pública en la delegación de Cartagena. Ese destino cambió en cierto modo su camino profesional ya que comenzó a vincularse también al ámbito de la arqueología, la cual le había interesado desde muy joven. Tanto es así que llegó a ser nombrado director del Museo Municipal de Arqueología de Cartagena y Delegado de las Excavaciones Arqueológicas de la ciudad. En 1963 fue nombrado Arquitecto Ayudante de la Séptima Zona de la Dirección General de Bellas Artes, convirtiéndose en la práctica en el máximo responsable del patrimonio histórico-artístico murciano, además de dirigir algunas intervenciones testimoniales en las provincias de Alicante y Almería. En 1973 fue también nombrado representante de la Dirección de Bellas Artes en Murcia, cargo que ostentaría a partir de 1979 para la ciudad de Cartagena. Desde 1976 fue, igualmente, Consejero Provincial de Bellas Artes ${ }^{1}$.

\footnotetext{
1 VV. AA., «In memoriam. Pedro Antonio San Martín Moro», Mastia. Revista del Museo Arqueológico Municipal de Cartagena, $\mathrm{N}^{\circ}$ 9, Segunda época, 2013, pp. 10-12; J. CASTILLO FERNÁNDEZ y J. C. MOLINA GAITÁN, «El fondo documental de Leopoldo Torres Balbás en el Archivo General de la Región de Murcia», en El legajo 57, R. FRESNEDA et al., Tres fronteras ediciones, Murcia, 2016, p. 41.
} 
San Martín vivió y murió en la ciudad cartagenera habiendo sido este uno de los lugares donde más trabajó, tanto en el campo de la arqueología como en el de la restauración monumental. Sacó a la luz y recuperó lugares como el anfiteatro romano, la necrópolis de San Antón (actual Museo Arqueológico) y participó en su última etapa profesional en el descubrimiento del teatro romano en el lugar donde se le había encargado previamente construir el Centro Regional de Artesanía. Sin embargo, su labor conservadora abarcó toda la Región de Murcia y todo tipo de monumentos.

En esta ocasión nos centraremos en las intervenciones de restauración que llevó a cabo en tres grandes ejemplos de la arquitectura civil murciana. En primer lugar, analizaremos el caso del Palacio de Guevara, sito en la localidad de Lorca, el cual fue intervenido especialmente en sus fachadas con el objetivo de devolver en cierto modo la imagen original a las mismas; en segundo lugar, haremos referencia a dos palacios que hoy solo conocemos por sus portadas, únicos elementos conservados y que fueron restauradas por San Martín: el Palacio de Riquelme y el Palacio del Contraste de la Seda, ambos en Murcia. Las circunstancias de estos monumentos eran muy distintas ya que mientras el Palacio de Guevara estaba aún en uso cuando San Martín lo intervino, los de Riquelme y el Contraste habían sucumbido al paso del tiempo, la desidia y el abandono hasta el punto de llegar a ser demolidos. De sus ruinas solo se salvaron las portadas que fueron, según el caso, desmontadas, trasladadas y/o remontadas en nuevos emplazamientos, permitiendo la perpetuación en el tiempo de la memoria de lo que habían sido sus lugares de origen.

\section{La restauración en estilo de un palacio en uso: el Palacio de Guevara}

El Palacio de Guevara, conocido en Lorca como el Palacio de las Columnas, es un gran ejemplo de arquitectura civil de finales del siglo XVII. Fue construido, en aquel entonces, extramuros de la población, junto a la ermita de San Agustín, por iniciativa del licenciado Juan de Guevara. La edificación que conservamos en la actualidad es el resultado de los añadidos y mejoras efectuadas por sus descendientes siendo su nieto, Juan de Guevara y García de Alcaraz, quien dotó a 
la construcción de algunos de sus elementos de referencia como, por ejemplo, la llamativa portada ${ }^{2}$.

Ésta fue construida en 1694, tal y como aparece grabado en la parte bajade su segundo cuerpo, y se hizo siguiendo la tradición decorativa churrigueresca. Se trata de un vano adintelado, flanqueado por dos columnas salomónicas y sendas pilastras decoradas con carnosas hojas de acanto. Los laterales se rematan con una suerte de aletones vegetales sobre los que parecen jugar dos putti que sostienen guirnaldas de frutas. La parte superior se asienta en una cornisa muy saliente, rota por un florón en cuyo centro aparece una máscara de un niño. Por encima se erigió majestuoso y de grandísimas dimensiones el escudo de los Guevara, sostenido por leones y flanqueado nuevamente por dos columnas torsas y dos figuras que sostienen el escudo de la familia de la esposa de Guevara y García de Alcaraz. El conjunto se completó en la parte alta con tres escudos de la Orden de Santiago, a la que pertenecía el dueño del inmueble. Interiormente, éste se articulaba alrededor de un interesante patio porticado y destacaba igualmente su escalera monumental. Constaba de 3 plantas estando la más baja destinada a dependencias de servicio, la principal a albergar la zona noble de la vivienda y la alta a cámaras, trasteros o "falsas", como las denomina la tradición local. Esas distintas plantas se muestran al exterior, especialmente la primera y la segunda mediante balcones de hierro forjado y arquerías de medio punto, respectivamente.

En el momento en el que San Martín intervino el palacio la dueña era $\mathrm{M}^{\mathrm{a}}$ Concepción Sandoval Moreno, Baronesa de Petrel y Mayalls y en los proyectos el arquitecto alude a como las obras fueron posibles gracias a su total y absoluta predisposición e interés. Así pues, en junio de 1967 y junio de 1970 San Marín Moro elaboró sendos proyectos para la restauración de esta residencia nobiliaria. El recinto estaba en buenas condiciones, tanto que el propio arquitecto hablaba de los numerosos tesoros artísticos que guardaba en su interior y de cómo en él existía un ambiente romántico que lo convertía en un verdadero museo. En consecuencia, lo que realmente se pretendía con los trabajos de conservación era devolver al monumento

2 E. FRANCO CÉSPEDES, F. J. FERNÁNDEZ GUIRAO, G. FERNÁNDEZ ILUNDAIN, «Intervenciones de urgencia en el palacio de Guevara,Lorca(Murcia)», Alberca.Revistadela Asociaciónde AmigosdelMuseo ArqueológicodeLorca, $\mathrm{N}^{\circ}$ 10, 2012, p. 196; J. GRANADOS GONZÁLEZ, «La restauración del patrimonio de Lorca en las décadas de 1960-1970. La obra de Pedro A. San Martín Moro», Alberca. Revista de la Asociación de Amigos del Museo Arqueológico de Lorca, $\mathrm{N}^{\circ}$ 8, 2010, p. 167. 
su imagen original eliminando los añadidos que habían desvirtuado su estética, algo especialmente constatable en sus fachadas. Antes de proseguir es preciso que aclaremos que, aunque en este estudio solo se hará referencia a los proyectos antes citados, los trabajos que San Martín llevó a cabo en el palacio se prolongaron en el tiempo y continuaron también durante los años 80 .

En la intervención de 1967 se restauró la fachada principal correspondiente a la calle Lope Gisbert mientras que en 1970 se intervinieron las fachadas laterales, todo con los mismos criterios que fueron los siguientes ${ }^{3}$ :

a) Se eliminaron los revocos modernos para sacar a la luz la mampostería y los ladrillos originales que se limpiaron y juntearon para asegurar su integridad y, donde fue necesario, se repusieron materiales. Se dejó el material a la vista, aunque con posterioridad se recubrió con cal como aparece en la actualidad.

b) La portada fue restaurada sustituyendo parte del material constructivo que se encontraba en mal estado para lo que fue necesario el apeo y desmonte de la misma.

c) Se abrieron los huecos de la arquería que recorría todo el edificio en su planta superior y se colocó en ella un pretil o barandilla de obra que recogería el modelo original.

d) Se creó un pasillo-galería en esa misma arquería mediante la colocación de un muro interior.

e) Se cerraron los vanos posteriores al planteamiento original y se abrieron algunos de los originales que se encontraban cerrados, restaurándolos y colocando, en su caso, rejas nuevas y antepechos.

f) Se eliminaron construcciones anexas que habían sido usadas como estancias de servicio que alteraban la visión del edificio y, por iniciativa del Ayuntamiento, se construyó en el espacio resultante una plaza.

g) Además, y siguiendo la tendencia habitual de este arquitecto, se dotó al edificio de una nueva iluminación, tanto interior como exterior, con el fin de mejorar su visualización y hacerlo atractivo al público en general, consiguiendo de este modo una mayor valoración del patrimonio local.

\footnotetext{
3 P. A. SAN MARTÍN MORO, Proyecto de restauración de la fachada del Palacio de Guevara, de Lorca, 1967. Archivo General de la Administración, Sección Cultura, Signaga: 26/00117 y Proyecto de restauración de la fachada del Palacio de Guevara, de Lorca (Murcia), 1970. Archivo General de la Administración, Sección Cultura, Signaga: 26/00176.
} 


\section{Desmontes, traslados y remontes: las portadas de los palacios de Riquelme y del Contraste de la Seda}

Durante su dilatadísima carrera profesional Pedro San Martín hubo de abordar proyectos muy variados entre ellos el de desmontar, trasladar y volver a montar algún monumento. En esta ocasión nos detendremos en dos ejemplos: la recuperación de las portadas del Palacio de Riquelme y del antiguo edificio del Contraste de la Seda, ambos situados en la ciudad de Murcia.

Esta modalidad de restauración no era excesivamente habitual, pero en nuestro país había sido ya trabajada en varios casos paradigmáticos y extremos con el fin de salvar de la desaparición definitiva algunas construcciones. Así pues, esta técnica había sido desarrollada con éxito por Alejandro Ferrant en la iglesia de San Pedro de La Nave en la provincia de Zamora en la década de los años 30 o por Francisco Pons Sorolla para el traslado y recuperación de la Iglesia de San Juan de Portomarín en Lugo en la década los $60^{4}$.

\section{La portada del Palacio de Riquelme}

Una de las construcciones más bellas que antaño formaban parte del patrimonio inmueble de la ciudad de Murcia era el Palacio de Riquelme. Fue construido a mediados del siglo XVI por encargo de la familia Riquelme Salafranca, marqueses de Pinares, escogiendo para su emplazamiento un lugar privilegiado en pleno centro: la confluencia de las calles Jabonerías y Platería. La fachada era uno de los ejemplos más antiguos de la arquitectura noble murciana, estando construida íntegramente en sillería de piedra. En ella sobresalía la espléndida portada compuesta por un potente arco de medio punto, flanqueado por dos medias columnas torsas de capitel dórico toscano que soportaban un entablamento donde se alojaba un segundo piso. En la

\footnotetext{
4 C. M. MARTÍN, «San Pedro de la Nave. Salvada del naufragio», Restauración \& rehabilitación, No 22, 1998 , pp. 30-35; F. J. OCAÑA EIROA, «Traslado y restauración de la iglesia románica de San Juan Portomarín», Abrente: Boletín de la Real Academia Gallega de Bellas Artes de Nuestra Señora del Rosario, №38-39, 2006-2007, pp. 21-50; B. M. CASTRO FERNÁNDEZ, «Rescate e interpretación del patrimonio cultural: la labor de arquitecto Francisco Pons Sorolla en Galicia», en Restaurando la memoria. España e Italia ante la recuperación monumental de posguerra, M. P. GARCÍA CUETOS, M. E. ALMARCHA NÚÑEZ-HERRADOR, A. HERNÁNDEZ MARTÍNEZ, A. (coord.), Trea, Gijón, 2010, pp. 108-113.
} 
parte superior aparecían las figuras de dos salvajes portando sendos pendonescuyos extremos servían para sujetar una guirnalda circular en cuyo centro aparecía el gran escudo de la familia. Éste se conformaba de un yelmo sostenido por el penacho por un brazo emergente de la parte superior, todo ello en campo de gules.Estos elementos hablaban del carácter guerrero de la familia, así como de su participación activa durante la Reconquista, algo especialmente presente en la imagen de los salvajes, símbolos de la vigilancia frente al invasor y el infiel ${ }^{5}$. Sobre esto se incluyó el vano principal de la portada, compuesto por una esbelta ventana ajimezada de tres huecos con columnas laterales estriadas que sostenían un entablamento que se remataba nuevamente con el escudo de armas. La portada se completaba con otros dos vanos, uno inferior adintelado y de frontón curvo y otro ajimezado doble con frontón partido, así como con un nuevo escudo familiar alojado justo en la esquina a modo de chaflán sujeto por dos leones.

El declive de la arquitectura monumental vinculada a las grandes casas nobiliarias de Murcia se inició en la primera mitad del siglo XIX, coincidiendo con la supresión del mayorazgo y la progresiva división del patrimonio en las herencias sucesivas. Todo ello culminó en décadas posteriores con un importante endeudamiento de las familias. La consecuencia directa fue la venta de numerosas casas y palacios imposibles de mantener ante las comprometidas circunstancias económicas que estaban atravesando ${ }^{6}$. Así pues, se tiene noticia gracias a Rodrigo Amador de los Ríos, de que el Palacio de Riquelme a finales del siglo XIX había dejado atrás su función originaria para albergar una casa de comidas. A principios del siglo XX en la parte dedicada a Murcia del Catálogo monumental de España. 1905-1907 ya se dice que lo único que había sobrevivido del edificio era la fachada y su decoración, lo cual nos permite deducir que la parte interior estaba ciertamente abandonada ${ }^{7}$. El palacio se mantuvo a duras penas en los años siguientes albergando en sus bajos diferentes usos comerciales.

Llegamos así a 1967, año clave para la historia del lugar. En ese momento ya se encontraba en ruinas, siendo declarado como tal por el Ayuntamiento el día 20 de

\footnotetext{
5 M. PÉREZ GARCÍA, «La conciencia de linaje a través de la representación heráldica: el ejemplo de la familia Riquelme (ss. XIII-XV)», Miscelánea medieval murciana, No XXVII-XXVIII, pp. 90-93.

6 F. CALVO GARCÍA-TORNEL, «Un ciclo cerrado: el patrimonio nobiliario construido en la ciudad de Murcia», Cuadernos de Turismo, № 27, 2011, pp. 82-83.

7 Íbidem, p. 85.
} 
enero y estando ya apuntalado en su totalidad. El propietario, José Rubio Hernández, informó a la Dirección General de Bellas Artes de la nefasta situación el 4 de febrero, concluyéndose que desgraciadamente la construcción ya no tenía salvación exceptuando una parte: su portada. Así pues, el día 12 de ese mes se propuso su desmonte y traslado con el fin de aprovecharla en el futuro en algún edificio público ${ }^{8}$. En ese momento entró en escena Pedro San Martín, al cual le encargaron la redacción del proyecto de recuperación de la portada fechado en junio de ese año. Además, fue él quien designó como nuevo emplazamiento la fachada de la ampliación del Museo Salzillo.

En el citado proyecto se establecieron varias fases de intervención?"

a) Fase de apuntalamiento de la fachada y creación de medidas de seguridad para la zona: la fachada, según narra el propio arquitecto, presentaba importantes grietas y se encontraba desplomada lo que había generado su desplazamiento con respecto al resto del inmueble (Fig.1). Eso motivó su total apuntalamiento con madera en piezas de gran sección para sujetar el enorme empuje producido por su peso. También se apuntalaron los vanos para evitar su deformación, así como algunos de los forjados del palacio que apoyaban directamente en la fachada. Paralelamente, y teniendo en cuenta el emplazamiento del palacio en una calle estrecha, se proyectó un paso cubierto hecho de ladrillo y forjado de madera para que los peatones pudieran transitar por allí sin problemas.

b) Colocación de los elementos necesarios para el desmonte: se trataba de un andamiaje metálico que cubría toda la fachada además de una torre grúa preparada para soportar y bajar hasta el suelo todos los sillares antes de ser trasladados en camiones. Estaba previsto que esta estructura se mantuviera al menos 90 días, tiempo mínimo que el arquitecto estimaba necesario para el desmonte.

c) Trabajos previos: se basaron en la limpieza de la superficie de la fachada con el fin de dejar al descubierto todas las juntas de unión entre los si-

\footnotetext{
8 P.A. SAN MARTÍN MORO, Propuesta de obras de terminación en la ampliación del Museo Salcillo [sic] y adaptación del Palacio de Riquelme (Murcia), 30 de abril de 1980. Archivo General de la Región de Murcia, PSM 10199/10,p. 1.

9 P.SAN MARTÍN MORO, Proyecto de desmontado y traslado de la fachada del Palacio de Riquelme, de Murcia, junio de 1967. Memoria. Archivo General de la Administración, Sección Cultura, Signaga: 26/00129, pp. 2-4.
} 


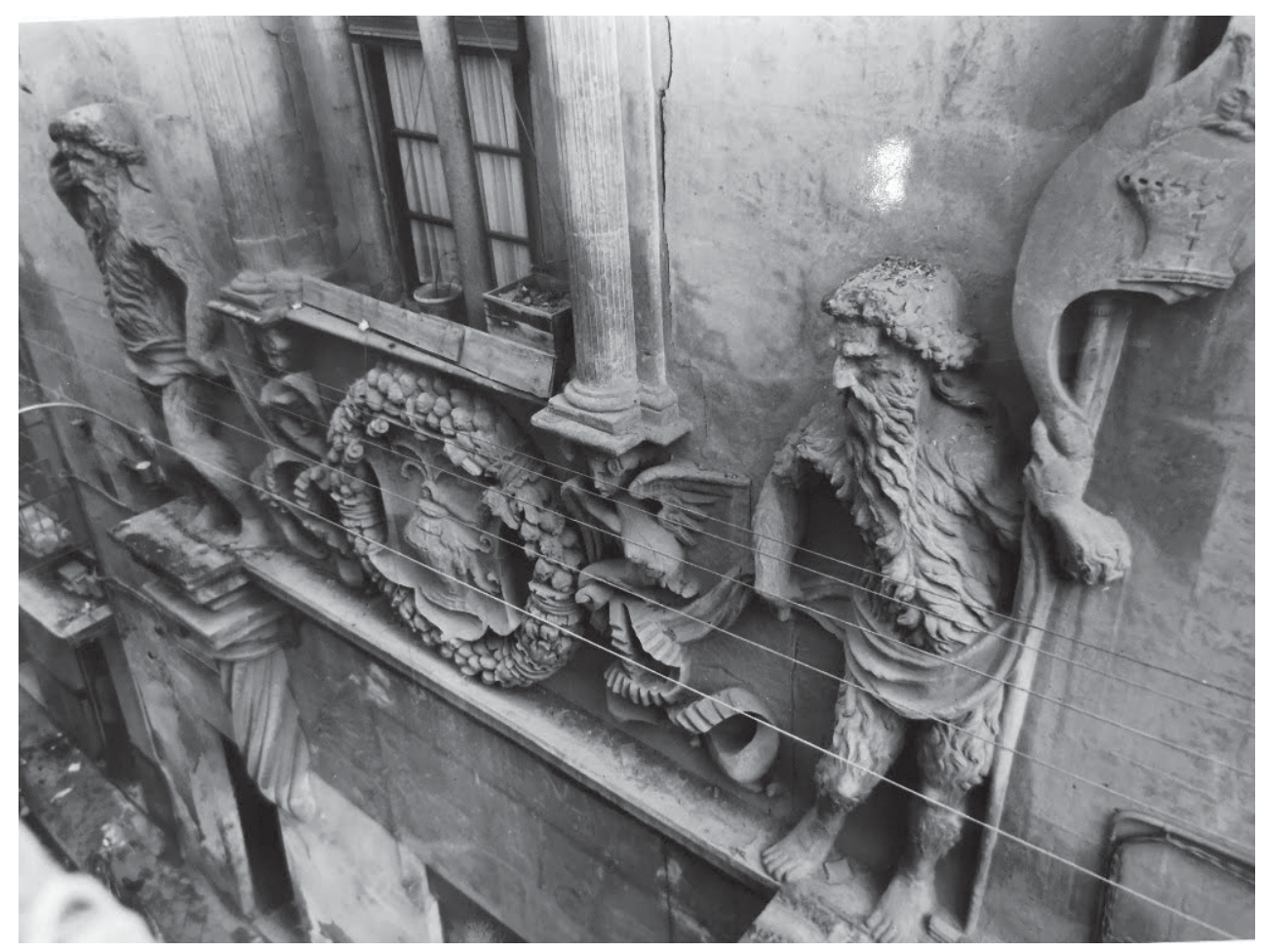

Fig. 1 Portada del Palacio de Riquelme en su localización original. Son visibles las enormes grietas que estaban dañando el conjunto. Archivo General de la Región de Murcia.

llares y así ayudar a la perfecta localización de éstos. Acto seguido estaba previsto realizar la medición y dibujo de la fachada con su despiece, numerando los sillares tanto en el plano como en la piedra. Finalmente, se harían fotografías de detalle por zonas para ayudar en la identificación de las piezas en el futuro montaje y recolocación.

d) Proceso de desmonte: para llevarlo a cabo, San Martín dividió la sillería en dos partes; por un lado, los sillares lisos y, por otro, aquellos que presentaban algún motivo labrado. Se procedió igualmente al descarnado de las juntas, apertura de huecos en las piedras para su mejor enganche, bajada de las mismas y, finalmente, su transporte encamiones.

e) Transporte: se haría en camiones de pequeño tonelaje, teniendo en cuenta la localización del inmueble intervenido. Además, se tendría 
especial cuidado con los horarios escogidos para llevar a cabo la tarea ya que era una zona comercial de importante tránsito público y se pretendía alterar lo menos posible el día a día del lugar.

f) Descarga y aparcamiento: se distribuirían ordenadamente las piezas en un solar colindante con el nuevo emplazamiento componiendo sobre el suelo totalmente la fachada facilitando así todo el proceso de montaje.

La portada desmontada se mantuvo allí durante algunos años hasta que en 1970 San Martín recibió un nuevo encargo: en esta ocasión debía acometer la colocación de la misma en su nuevo emplazamiento ya que el solar donde reposaban sus sillares fue requerido por el Ayuntamiento local con el fin de abrir allí una nueva calle incluida en el proyecto de ampliación del Museo Salzillo. Éste se encontraba adosado, por un lado, a la Iglesia de Jesús y, por el otro, a una casa particular que acababa de ser derribada para abrir la nueva vía. El Ayuntamiento aprobó ceder al Ministerio de Educación de la época una parte del solar con el fin de adicionarla al museo ya que, una vez proyectada la calle, era terreno sobrante ${ }^{10}$.

Así pues, en la memoria de un nuevo proyecto fechado en junio ${ }^{11}$ se detallaron todos los trabajos previstos que iban básicamente encaminados al montaje de la portada. Para ello, se proyectó la construcción de un cuerpo de edificio inmediato al museo, previo apeo y recalces de las medianerías que presentaban un estado deficiente. Contaría con una cimentación de hormigón en masa que tendría en determinados puntos zunchos de sujeción de la base de los cimientos existentes sobre hormigón. Estaba previsto que los muros exteriores se construyeran en ladrillo macizo con mortero de cemento y tabicones de ladrillo hueco. La planta baja contaría con solera de hormigón y los forjados de los diferentes pisos serían de estructura de hierro apoyada en zunchos, nuevamente de hormigón armado, apoyados en los muros de carga. Los extremos de las vigas sobresaldrían en la fachada para servir de apoyo a la portada del palacio que recaería directamente sobre los

10 P. A. SAN MARTÍN MORO, Proyecto de montaje de la fachada del Palacio de Riquelme para la ampliación del Museo Salzillo en la Iglesia de Jesús de Murcia, junio de 1970. Memoria. Archivo General de la Administración, Sección Cultura, Signaga: 26/00175, p. 1.

11 Íbidem, pp. 1-2. En esta ocasión el proyecto no aparece firmado en solitario por San Martín, sino que lo acompaña José Tamés Alarcón, su predecesor en el cargo de Arquitecto de Zona para la Dirección General de Bellas Artes. Además, Tamés fue uno de los impulsores ya en los años 50 de la ampliación del Museo Salzillo. 
ladrillos previa limpieza y engrapado de los sillares. Para todo ello se dio un plazo de unos 6 meses de trabajo.

En abril de 1971 San Martín redactó el proyecto de la segunda fase de lostrabajos que habrían de culminar la colocación de la portada de los Riquelme en la nueva fachada, así como terminar los nuevos espacios añadidos al museo. Se diseñó una cimentación de hormigón sobre la que iría la portada y se propuso el uso de ladrillos para cerrar la fábrica de la nueva fachada. El paramento exterior se enluciría con mortero de cemento, se colocaría rejas y carpintería de madera en los vanos y se remataría todo con un alero de madera con canecillos y ménsulas metálicas ${ }^{12}$. Estas obras previstas se materializaron a lo largo de 1972 suponiendo la construcción de la fachada y la portada solo en su mitad inferior ya que las obras tuvieron que pararse por falta de presupuesto en el mes de noviembre.

Por tanto, cuando todo iba bien y parecía que la integridad de la portada estaba por fin a salvo, las obras de su nuevo emplazamiento quedaron paradas entre los años 1973 y 1980 dejando el proyecto sin cerrar. Así, a lo largo de ese tiempo hubo continuos intentos por parte del arquitecto para acabar el proyecto solicitando presupuestos complementarios o nuevos proyectos que fueron sistemáticamente denegados ${ }^{13}$. La situación era tan triste que hasta la prensa se hizo eco en esos años de la dejadez por la que pasaban las obras inacabadas y las piezas de la portada que aún no se habían colocado y que seguían abandonadas en un solar junto al museo (Fig. 2) ${ }^{14}$. Finalmente, las obras se acabarían en los años 80 convirtiendo la portada del Palacio de Riquelme en una entrada lateral al Museo Salzillo que en la actualidad está en pleno uso (Fig. 3).

\section{La portada del Contraste de la Seda}

El Contraste de la Seda era una gran construcción civil del siglo XVII situada en un hito del centro urbano de Murcia: la plaza de Santa Catalina. Estaba dedicado

\footnotetext{
12 P. A. SAN MARTín MORO, Proyecto de montaje de la fachada del Palacio de Riquelme para la ampliación del Museo Salzillo en la Iglesia de Jesús de Murcia, $2^{\text {a }}$ fase, abril de 1971. Memoria. Archivo General de la Administración, Sección Cultura, Signaga: 26/00323, pp. 1-2.

13 P.A. SAN MARTÍN MORO, Propuesta de obras de terminación..., p.2.

14 Véase el artículo «Una restauración arquitectónica a medias» en el periódico Línea, 6 de septiembre de 1977, pp. 16-17. Archivo General de la Región de Murcia, PSM 10199/10.
} 


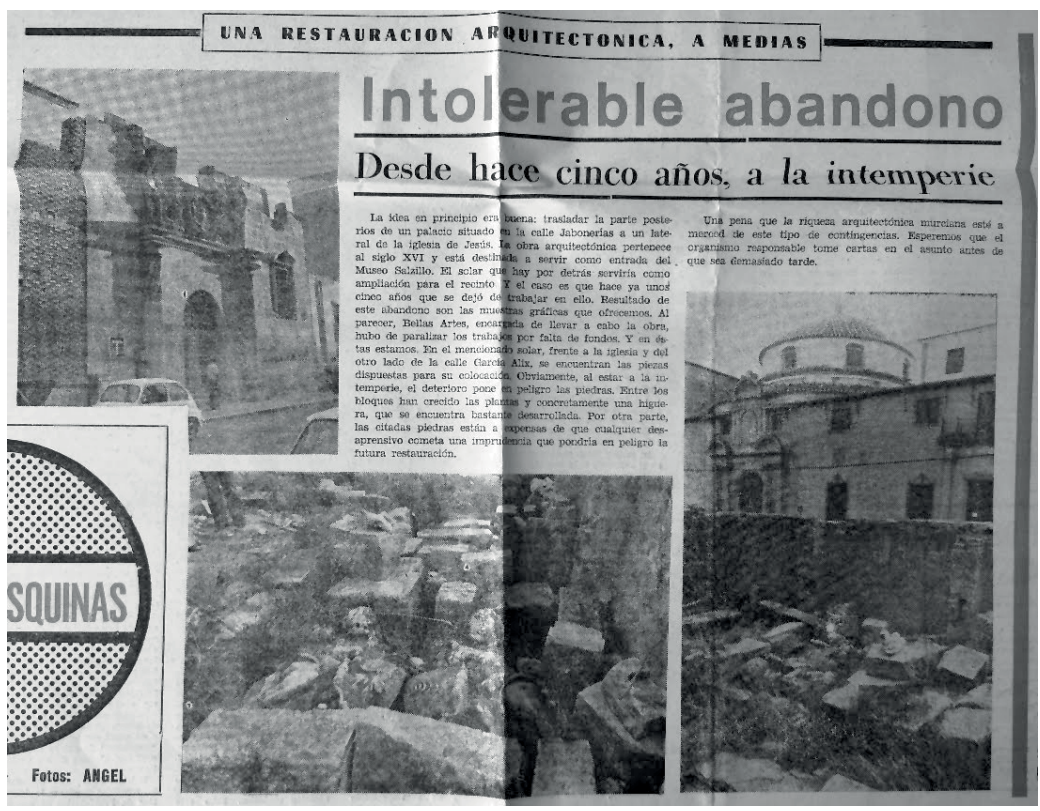

Fig. 2 Recorte de prensa de la revista Linea con el artículo «Una restauración arquitectónica a medias» publicado el 6 de septiembre de 1977. Archivo General de la Región de Murcia.

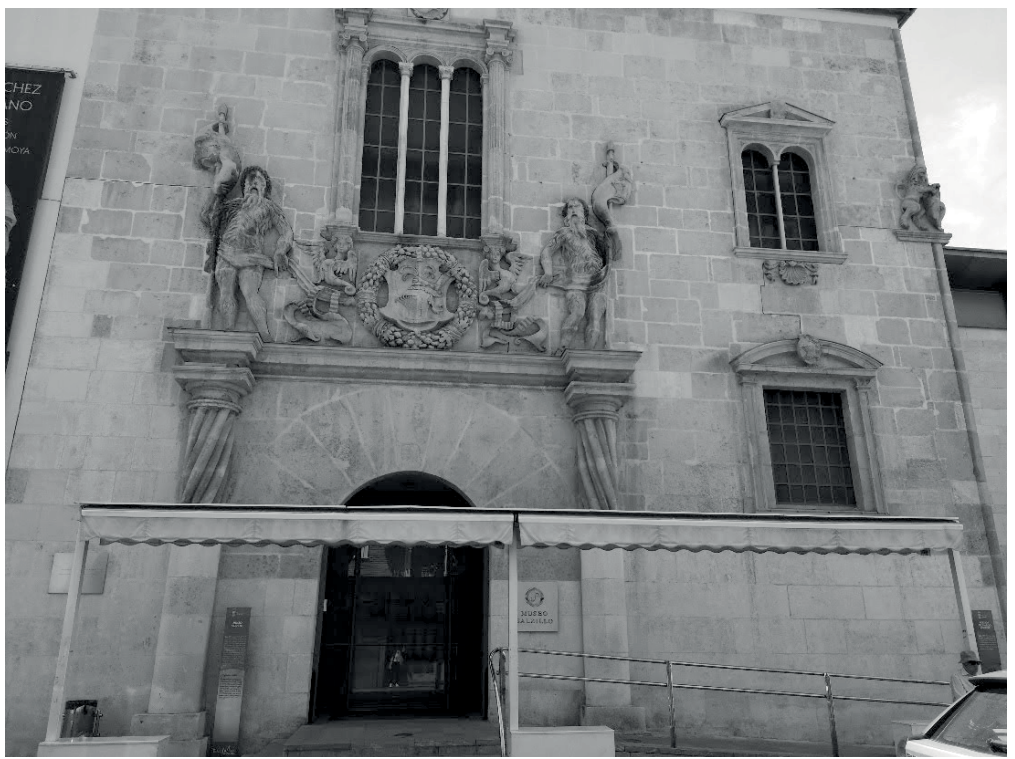

Fig. 3 Portada del Palacio de Riquelme en su emplazamiento definitivo. Fotografía de la autora. 
al desarrollo de actividades relacionadas con el comercio del material que le daba nombre, lo que lo convirtió en el centro de reunión de mercaderes y de todos aquellos relacionados con el mundo de las telas y la confección. Aunque esa fue su función principal, el edificio también se utilizó como sede del Concejo, como lonja, como almacén de guerra, como sede de la inspección del cambio de monedas de oro y plata, como calabozo y como archivo.

Se construyó entre los años 1601 y 1609 siendo su arquitecto Pedro Monte de Isla, Maestro Mayor de la Catedral de Murcia. Estilísticamente se trataba de un edificio peculiar ya que no terminaba de responder al estereotipo de arquitectura barroca del momento. Era una construcción anclada todavía en el Renacimiento y con una clara influencia de Serlio y Vignola, algo especialmente presente en sus portadas. Se considera pues que este palacio vendría a ser una manifestación tardía del Manierismo del siglo XVI ${ }^{15}$. Toda la organización del edificio bebía de la de los palacios renacentistas italianos. Se trataba de un inmueble donde predominaba la horizontalidad contando con tres alturas: la planta baja,la planta noble y una galería superior. Además, en el interior existía un patio porticado que imitaba a los cortiles italianos. Exteriormente, los elementos decorativos que conformaban sus portadas y enmarcaban sus vanos volvían a recordar al más puro estilo clásico con pilastras, entablamentos y frontones curvos y triangulares, algunos de ellos partidos, y pirámides de tradición herreriana. Todo ello se completaba con el escudo real que se repetía en varias ocasiones.

A pesar de la importancia lograda, el lugar fue poco a poco decayendo. Al propio efecto generado por el paso del tiempo debemos añadir que quedó bastante dañado en 1827 tras un terremoto que ocasionó la pérdida de la galería superior. A finales del XIX el Ayuntamiento comunicó en varias ocasiones a la Comisión de Monumentos el estado ruinoso del edificio hasta el punto de solicitar el desalojo urgente del mismo. A pesar de todo, continuaba en uso ya que en su planta alta estaba alojado entonces el Museo de Bellas Artes, pero ante la imposibilidad de trasladar las obras a

15 C. BELDA NAVARRO, E. HERNÁNDEZ ALBALADEJO, Arte en la Región de Murcia. De la Reconquista a la Ilustración, Consejería de Educación y Cultura, Comunidad Autónoma de la Región de Murcia, 2006, p. 243; C. BELDA NAVARRO, «El Contraste de la Seda y las reformas urbanísticas de la plaza de Sta. Catalina (Murcia) en los comienzos del siglo XVII», Anales de la Universidad de Murcia. Filosofía y Letras, Vol. 30, № 1-2, 1972, p. 132. 
un lugar más adecuado se acordó acometer algunas mejoras en el inmueble con el fin de perpetuar su ya maltrecha existencia ${ }^{16}$. Así, y aunque en 1922 había sido declarado Monumento Nacional, su destrucción fue imparable y en 1932 fue definitivamente derruido. Como ocurriera con el caso que hemos analizado antes, de todo el conjunto solo se logró conservar las portadas de las fachadas norte y oeste que fueron desmontadas y convenientemente trasladadas al Museo de Bellas Artes de la ciudad que ya contaba con su sede definitiva.

En 1970 se encargaron a Pedro San Martín las tareas de ampliación del citado museo y durante la reforma localizó en el patio del edificio los sillares procedentes de una de las portadas del Contraste. La que fuera portada principal ya había sido recolocada en el fondo del patio del museo tras haber sido restaurada por Leopoldo Torres Balbás entre 1930 y $1934{ }^{17}$ dando entrada a lo que hoy se denomina como "Pabellón Contraste". Sin embargo, la portada que nos ocupa había permanecido desmontada durante años. La belleza y el gran interés histórico y artístico que tenían aquellos restos, así como la necesidad de dejar libre el patio donde estaba previsto construir un depósito de cuadros, hizo que el arquitecto propusiera montarla de forma urgente y colocarla en el mismo patio, concretamente en uno de sus ángulos cerca de la otra portada (Fig. 4 y 5).

La manera de proceder en la recuperación de este elemento fue muy similar a la desarrollada durante el montaje de la portada del Palacio de Riquelme especificando en la memoria del proyecto ${ }^{18}$ de 1972 los siguientes pasos a seguir:

a) Traslado de los sillares desde su emplazamiento hasta entonces al patio donde se reconstruiría la portada.

b) Construcción de una zapata de cimentación de hormigón armado sobre la que se pretendía colocar la estructura recuperada.

c) Construcción de dos pilares a modo de contrafuertes de hormigón armado que por la parte superior de la fachada harían de contrapeso y atirantarían las pilastras y el entablamento de la portada.

16 A. MARTÍNEZ MENA-GARCÍA, «La destrucción del patrimonio arquitectónico y su reflejo en la ciudad de Murcia», Imafronte, No 17, 2003-2004, p. 139.

17 A. MÚÑOZ COSME, La vida y la obra de Leopoldo Torres Balbás, Junta de Andalucía, Sevilla, 2005, p 98.

18 P.A. SAN MARTÍN MORO, Proyecto de montaje de la fachada del Contraste en el patio del Museo de Bellas Artes de Murcia, junio de 1972. Memoria. Archivo General de la Administración, Sección Cultura, Signaga: 26/01670, p. 1. 


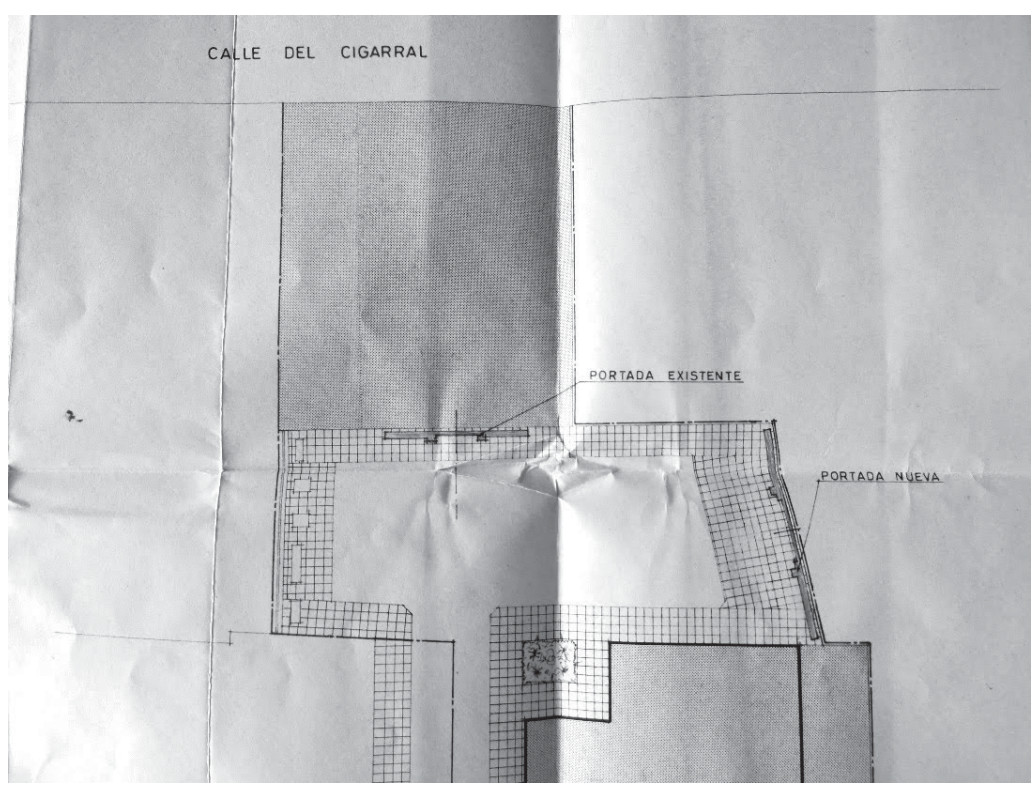

Fig. 4 Plano de colocación de la nueva portada. Proyecto de 1972. Archivo General de la Región de Murcia.

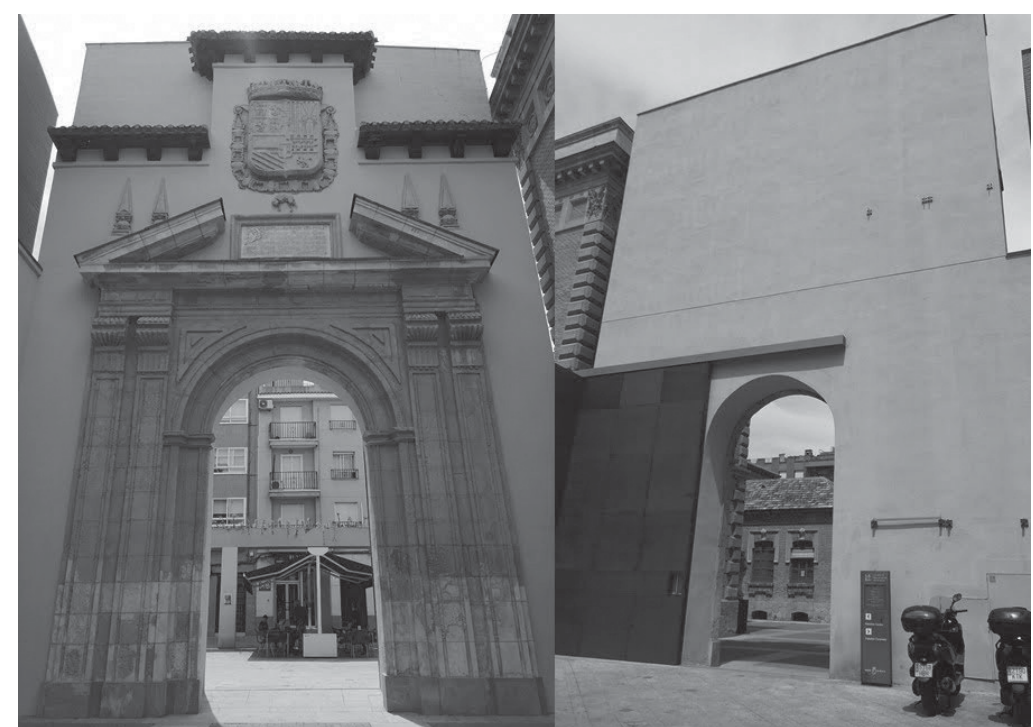

Fig. 5 Portada del Contraste en su emplazamiento actual. Frente y parte posterior. Fotografía de la autora. 
d) Levantamiento de la portada utilizando todos los elementos originales conservados previamente numerados (Fig. 6) y sustituyendo las piedras faltantes que ascendían al 20\% del total. Las piezas nuevas se harían en piedra natural buscando un acabado lo más parecido posible a las originales.

e) El fondo de la fachada donde se colocaría la portada sería liso, hecho de ladrillo y con un enlucido de acabado neutro para no desentonar con el entorno ni entorpecer la visión de la portada recuperada.

f) Además, se incorporó una puerta nueva de madera con dos hojas en la que se reutilizaron los herrajes de la puerta original que por su estado de conservación resultó ser inaprovechable.

g) Finalmente, y como solía ser común en los proyectos de San Martín, propuso la conveniente iluminación del conjunto.

A día de hoy, la portada sigue colocada en ese mismo lugar, presentando una imagen muy similar a cómo la dejó San Martín y en cuya base todavía son visibles algunas de las partes de piedra que fueron repuestas entonces. Curiosamente resulta llamativo comprobar que este magnífico trabajo realizado por nuestro arquitecto ha pasado desapercibido para el imaginario colectivo de la ciudad. Así pues, es bastante habitual encontrar la errónea información de que la recuperación de esta portada en concreto fue llevada a cabo por Torres Balbas a la vez que restauraba la portada principal. Sin embargo, la rica documentación conservada, así como determinadas fotografías antiguas, muestran que el rescate de las portadas del Contraste tuvo dos fases, la de Torres Balbás y la de San Martín Moro, de manera que su recuperación es fruto de dos acciones separadas en el tiempo.

\section{Conclusiones}

Muchas localidades murcianas han tenido que enfrentarse a lo largo de los siglos con el deterioro y, en algunos casos, la pérdida casi imparable de buena parte de su patrimonio monumental debido a causas muy diversas: desde los efectos generados por fenómenos naturales a la dejadez y desidia del hombre prolongada en 


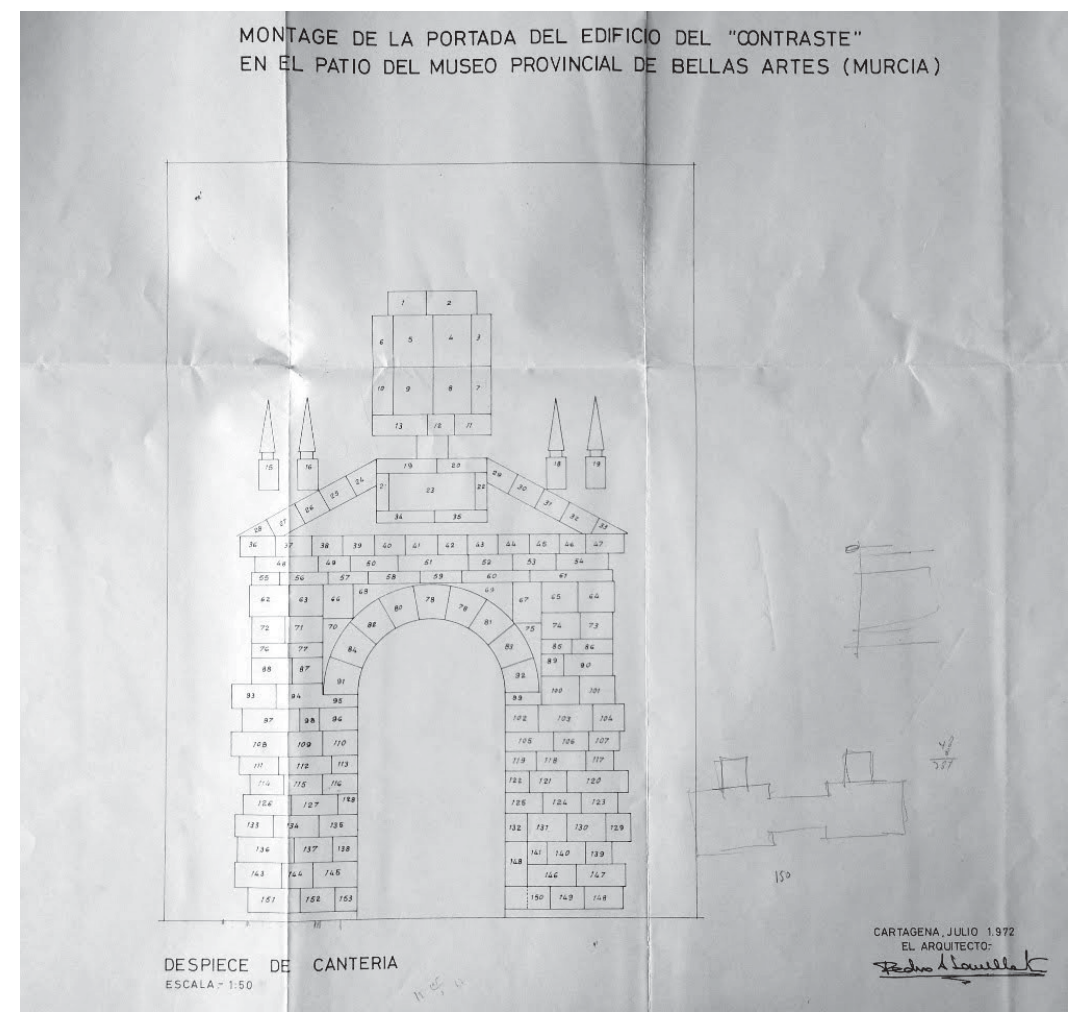

Fig. 6 Plano del despiece de cantería de la portada del Contraste. Archivo General de la Región de Murcia.

el tiempo. Desgraciadamente, en numerosos casos solo conocemos la existencia de aquellos lugares gracias a los esfuerzos de unos cuantos entre los que destacan los arquitectos restauradores como Pedro San Martín Moro.

Su amplio legado permite conocer la ardua tarea que desarrolló durante años lo que lo convierte, sin duda, en uno de los grandes artífices de la restauración de monumentos contemporánea en nuestro país. Sin embargo, y a pesar de que en lugares como Cartagena es muy conocido y reconocido, su trabajo ha permanecido oculto durante años. Es habitual encontrar en libros de historia de la restauración monumental española grandes nombres como Alejandro Ferrant, Luis Menéndez Pidal, Francisco Prieto Moreno, Félix Hernández Giménez, Francisco Pons Sorolla o 
Fernando Chueca Goitia, por citar solo unos ejemplos, y es entre ellos donde también debiera aparecer San Martín. Con ese objetivo y con el de reivindicar su figura surge este artículo centrado en una pequeñísima parte de su obra.

Como hemos visto, sus intervenciones permitieron conservar, completamente o en parte, ejemplos fundamentales del legado artístico murciano, orientando sus trabajos hacia dos vertientes diferentes que ponen de manifiesto la gran versatilidad de nuestro arquitecto: por un lado, abordó restauraciones estéticas de raigambre estilística al más puro estilo decimonónico, como hemos visto en Lorca y su Palacio de Guevara y, por otro, afrontó proyectos más arriesgados y complejos como los de recuperar los restos olvidados de las portadas de Riquelme y del Contraste para así brindarles una segunda oportunidad. La restauración de las mismas y su remonte hizo posible materializar la memoria de lugares que jamás volveremos a ver, siendo testigos mudos del olvido y sirviendo de recordatorio continuo de lo que se pudo haber hecho y nunca se hizo. 